\title{
The Intercultural Adaptation of the Pakistani Students at Chinese Universities
}

\author{
Xiaoqing Su \\ School of Foreign Languages, Northwestern Polytechnical University, China
}

Copyright $\bigcirc 2017$ by authors, all rights reserved. Authors agree that this article remains permanently open access under the terms of the Creative Commons Attribution License 4.0 International License

\begin{abstract}
In the past decade, the population of international students enrolling in Chinese colleges and universities has been increasing rapidly, with the students in Asia taking the most portions. Chinese higher education institutions are facing great challenges in their course of internationalization. Therefore the studies on the intercultural adaptation of international students in Chinese higher education institutions have received extensive attention. The present research was conducted to investigate the intercultural adaptation of the Pakistani students at the Chinese universities in forms of a questionnaire and interviews. Colleen Ward's cultural adjustment process model is used as the analytical lens to explore the life and study experiences of the Pakistani students from their perspectives and to understand the challenges they experienced during their intercultural communication. The students' personal reports will collectively provide some valuable information for Chinese universities to understand cultural differences that international students is bringing to Chinese campuses and to help them succeed in a totally different academic setting.
\end{abstract}

Keywords Intercultural Adaptation, Pakistani Students, Chinese Universities

\section{Introduction}

In the past decade, especially with the implementation of China's Belt and Road initiative, the population of international students enrolling in Chinese colleges and universities has been increasing rapidly, with the students in Asia taking the most portions. Chinese higher education institutions are facing great challenges in their course of internationalization. Therefore the studies on the intercultural adaptation of international students in Chinese higher education institutions have become a popular topic.

People's Republic of China and The Islamic Republic of Pakistan has established strategic cooperative partnership which has being further enhanced by the recent implementation of the China-Pakistan Economic Corridor, the flagship project of the Belt and Road Initiative. The bilateral exchanges and cooperation in various fields deepened between the two countries, especially in tertiary education. In wake of China Pakistan Economic Corridor (CPEC) project, the number of Chinese Government Scholarships for Pakistani students has increased to 600 a year. According to the statistics announced by Chinese Ministry of Education in 2015, the number of Pakistani students studying in China ranks the fourth among the students number from the Asian countries after South Korea, Thailand, and India, and outdoes the number of students both from Britain and America in 2015. Compared to the year 2005, the figure has multiplied by 7.1 times in 2015.

Although China and Pakistan are neighboring countries, students who travel to China to study are facing a very different environment from the one they grew up in. They inevitably experience some level of culture in adjustment or culture shock as their usual ways of communicating and socializing prove inadequate or inappropriate. As the number of Pakistani students on Chinese campuses has risen, researches on how the sojourners and immigrants adapt to a new cultural environment and on ways Chinese hosts can help the sojourners adapt to their new environment have become of great significance. Therefore, discussing the theory of intercultural adaptation and the role of the host environment in facilitating this process will not only help Pakistani students to better adapt themselves in Chinese culture, but also provide guidance or suggestions for the counselors, faculty, and host students to communicate effectively with the students coming from Pakistan.

\section{Literary Review}

As globalization facilitates a greater array of intercultural interactions, issues on how to promote intercultural communication and to reduce the ethnocentric view of people have generated wide interest in varied 
academia. Fostering intercultural adaptation when people study abroad plays a vital role in this endeavor.

A sojourn is defined as a temporary stay in a new place which occurs voluntarily for an unspecified, though relatively short period of time. Although there are no fixed criteria for defining a sojourn in terms of its duration, 6 months to 5 years are commonly cited parameters. Consequently, student and business sojourners are usually more committed than tourists to their new location, but less involved than immigrants and resettled refugees. According to Ward [1], like immigrants, they voluntarily relocate abroad; however, 'returning home' is anticipated and planned.

According to Chen \& Starosta [2], intercultural adaptation referred to the process by which sojourners deal with and adjust to a completely new cultural environment. Chen \& Starosta [2] acknowledged that "as we move toward multiculturalism and globalization, it is not only the business world that must adapt to these changes; the academic sector must deal with the trend as well". Yang, Noels, and Saumure [3] explained that intercultural adaptation includes transformations of the traveler's way of feeling, thinking, and behaving. Several studies [1][3][4] have dealt with the experience of cross-cultural adaptation not only to understand the successful adaptation of the sojourners but also the quality of interactions between people from different cultures. These interactions are of specific interest to intercultural communication research. The main focus of intercultural communication research has been on the direct interactions of individuals who have various cultural backgrounds.

Based on extensive and detailed studies of foreign students and sojourners by Colleen Ward and her colleagues [1], they stated that the process of acculturation should be tested in terms of "two conceptually distinct but empirically related adjustment outcomes"--a distinction between psychological (emotional/affective) and socio-cultural (behavioral) adaptation [5][6]. These two dimensions of adaptation are interrelated; dealing successfully with problems and positive interactions with members of the dominant culture. The figure of the model of Colleen Ward's intercultural adaptation process is as follow:

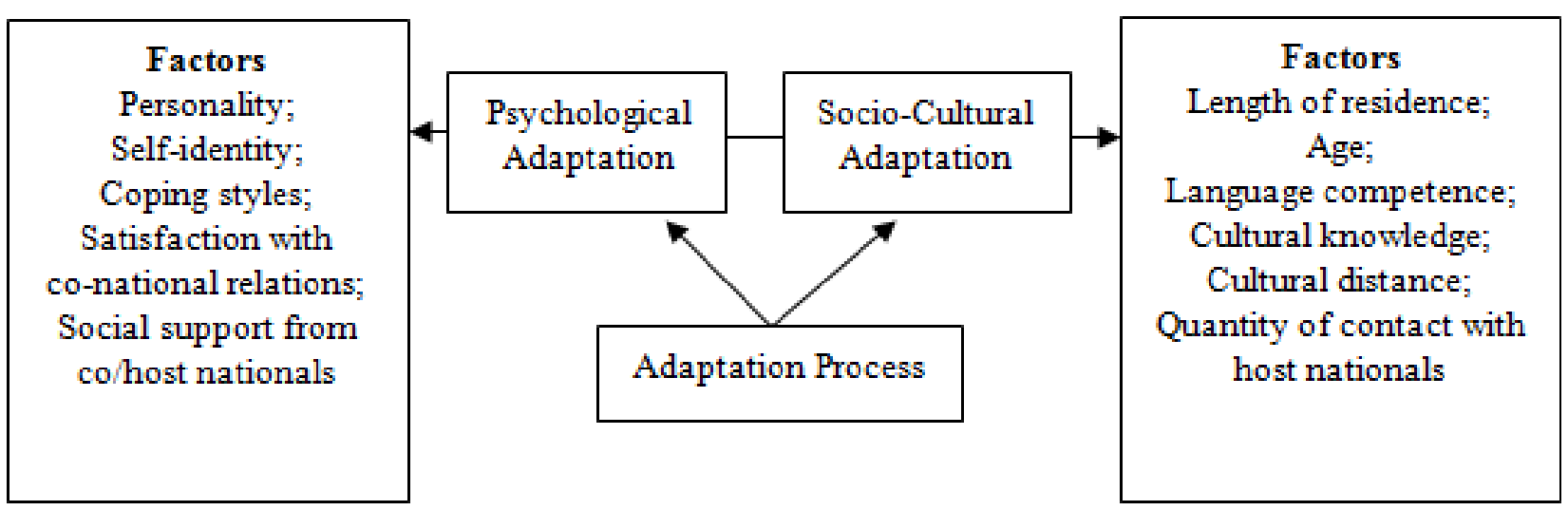

Figure 1. Intercultural Adaptation Process Model (Colleen Ward, 1992) 
Ward illustrated, socio-cultural adaptation, based on a social learning perspective [7, 8], refers to acquiring culturally appropriate knowledge and skills, and thereby, to develop one's ability to effectively interact with members of the host culture and to deal effectively with everyday life situations. Socio-cultural adaptation is related to the ability to "fit in" or negotiate interactive aspects of the host culture. It is predicted by variables that are related more strongly to cognitive factors and social skills acquisition, such as cultural knowledge, cultural distance, cultural identity, language ability, length of residence in the new culture, and amount of contact with hosts.

Psychological adaptation is associated with stress and coping framework, which refers to psychological well-being and satisfaction in a new cultural context. Researches have shown that psychological adaptation, defined in terms of well-being or mood states (e.g. depression, anxiety, tension, and fatigue), is predicted by personality, life changes, and social support variables. The locus of control, life changes and personal relationship satisfaction accounted for a substantial portion of variance in psychological wellbeing in student and adult sojourners.

The literature on oversea students is varied, but it is generally concentrated in fairly narrow areas. Much research has been carried out on topics such as the attitudes and adaptation problems of Chinese students in European and North American universities, yet research on the status of adaptation of international students in China is relatively inadequate.

\section{Methodology}

This study aims to examine the intercultural adaptation of the Pakistani students at Chinese universities from the aspects of psychological adaptation and socio-cultural adaptation, through the data analysis of a survey and the interpretive research on students' personal reports collectively. Colleen Ward's cultural adjustment process model is used as the analytical lens to explore the life and study experiences of the Pakistani students from their perspectives and to understand the challenges they experienced during their intercultural communication on Chinese campuses. The students' personal reports will collectively provide some valuable information for Chinese universities to understand cultural differences that international students is bringing to Chinese campuses and to help them succeed in a totally different academic setting. Through the participants' stories and their narratives, the meaning of their experience is constructed. An interpretive approach is considered the sub elementary research designed to examine the complex concepts of intercultural adaptation.

\section{Sample and Procedure}

The survey was administered in the form of a questionnaire given to 247 Pakistani students (226 of male, 21 of female) who are currently studying at Chinese higher education institutions through Sojump, an online survey software and questionnaire tool. The group was fairly large and accessible, which consist of 93 doctorate students, 96 and 58 for post-graduate and undergraduate students respectively. 136 of the participants responded that they did not study Chinese language before coming to China. 29 of the students claimed that they can communicate orally and have the basic skills of Chinese language.

The questionnaire was designed in English with all the questions designed on 5-point Likert Scale, except demographic questions. The questionnaire constituted demographic information, measures of socio-cultural adaptation and psychological adaptation. Demographic questions included gender, study level, marital status, and prior Chinese language level. The data were then analysed using SPSS Version 22.0 for Windows.

Ten of the respondents were voluntarily recruited as interviewees through snowball sampling. Three were PHD students, five were masters and two were bachelors. Eight were male and two were female. The ages range from 18 to 34 years. Informed consent was obtained from all of the participants. Face-to-face or online (through Wechat, a Chinese social media platform) semi-interviews were conducted for 45 to 60 minutes for one participant. 10 open-ended questions were designed to allow the participants to consider the research topic, that is, the process of intercultural adaptation in Chinese university settings. All interviews were either audio or text recorded. Transcripts were made directly from the recording. The written transcripts were then analyzed.

\section{Data Analysis and Discussions}

Colleen Ward's cultural adjustment process model served as the basis for the analysis of the data. The two dimensions of the model were used as categories into which emerging themes from the text were coded. The goal was to find evidence for the different dimensions of the model and to examine their specific relationships in the process of intercultural adaptation.

In terms of psychological adaptation, the results of the questionnaire show that $87 \%$ of the Pakistani students are satisfied with their interaction with the co-nationals and the host culture, and they are having a subjective and sense-making experience in China. As it is stated in one of the interviews,

"...I enjoyed the culture of China, the hospitality of Chinese people and the historical places. Chinese culture is a beautiful combination of many traditions. I hope when I go back, I found myself a better person than before...."

The results also indicate that the respondents' coping styles and communication styles influence students' 
adaptation to the host culture. There is not a high level of stress revealed in the results. The greatest block to adaptation is the lack of intercultural communicative competence.

As the results reveal, Pakistani students' perceptions about social support they receive from family, friends and university staff minimize the challenges and stress they face in China. As mentioned by Sumer et al. [8], anxiety and depression are associated with social support. Hence, international students' perception of receiving social support helps them overcome their depression and anxiety resulting in better psychological adaptation. Besides, by increasing more knowledge about the new environment and interaction with host nationals, students achieve better sociocultural adaptation.

As for socio-cultural adaptation, it appears that $89 \%$ of the respondents' adaptation is positively correlated with the length of stay in China. For instance, one interviewee mentioned,

"...I thought China was just temples, beautiful lakes, historical sites and so on. I'm now reaching the third year in China and my views on China have changed multiple times. All I learned so far is that 'The more I see, the less I know'..."

According to the data analysis, sojourners' length of residence greatly affects their adaptation. The degree that sojourners' contact with the co-nationals can create an impact on their adaptation to the host culture. $83.37 \%$ respondents claimed that they spent most of their spare time with their co-nationals.

In the present survey Chinese language proficiency is another factor for sojourners' adapting to the host culture. Language proficiency positively influences international students' sociocultural adaptation. The investigation reveals that $91 \%$ of the respondents experience a general cultural shock in which basic everyday experiences such as how to find an apartment, where to shop for groceries, how to ask for help, and where to go to meet other students create exciting and potentially troublesome situations. For instance, two students stated in the interview that,

"...After settled in my dormitory, I relieved after a long time. But very soon my anxiety merged again when I went to market to buy stuff. I realized that because I'm not able to speak Chinese, I could encounter numerous problems even doing some primary things like shopping or eating food at a restaurant. I became even more depressed when I learned almost half of the courses provided by my university were taught in English..."

"...At the beginning, I could only understand the hand signals of Chinese people but sometimes even I didn't understand them..."

Self-perception of possessing Chinese language proficiency shapes up Pakistani students' confidence in the different academic setting and results in lower level of stress and anxiety in China. It also helps them communicate with other students resulting in more interaction and cultural learning.

Simultaneously, students are adapting to their new educational environment in which language barriers, relationships with professors, staff and peers, the process of learning, a different time schedule and even different food are additional problems cast onto their intercultural adaptation. For example, one student mentioned,

"...In the beginning, I couldn't taste the Chinese food, everyday rice and noodles, but later I got used to this food. I've found out many types of delicious food, not just rice and noodles as I thought before..."

In terms of sociocultural adaptation, the low level of willingness to interact with host people results in lack of knowledge about the host country and lower sociocultural adaptation. Nevertheless, the tendency towards upholding original cultural norms and values helps students experience less stress and anxiety.

It is evident from the above discussion that the findings confirmed the importance of the dimensions put forward by Ward [1]. Most importantly, all respondents express a substantial change during their study in China, suggesting that intercultural adaptation lead to profound personal transformations. They report transformation in their perspectives and attitudes toward others. They recognize that through studying abroad, they can better understand culture differences and even develop a profound understanding of their own culture. Their satisfaction with the relationship with the host culture is described in their reports. They note that they very positively evaluate their intercultural experiences, especially with regards to their relationships with Chinese people. This process of intercultural adaptation is influenced by both personal and social communication factors. In respondents' interview reports, it is indicated that three factors of personal communication -- language ability, adaptive motivation, and flexibility - facilitate their adaption to Chinese culture. In other words, their overall capacity to encode and decode the information in the new environment and culture appropriately helps them easily adjust to their life and study in China. Also, they described that they had formal and informal contacts with the locals. The more they communicate with hosts, the more opportunities to learn about the hosts' culture they have. Therefore, both personal and social communications affect successful intercultural adaptation. Without the impact of the environment, intercultural adaptation cannot be fully understood. All participants said that they felt the hosts expressed hospitality. This means that hosts' positive attitudes toward the sojourners greatly influence intercultural adaptation.

To sum up, the findings suggest that Ward's model is plausible in explaining how these factors combine to affect the students' adaptation to the new culture. From a pragmatic perspective, the current study provides insights 
as to how intercultural adaptation can be fostered and examines intercultural adaptation in the context of Pakistani students studying in China.

\section{Summary}

On the basis of the above findings, the following suggestions are put forward to help improve the quality of the international education for Chinese universities and intercultural adaptation of international students studying in China. First, proper orientation on Chinese education system is crucial to minimizing students' problems. If students could know in advance the grading system and classroom environment, they would be psychologically prepared for their academic life at Chinese universities. Second, as Chinese language competence plays a very important role in students' psychological and socio-cultural adaptation, some pre-departure intercultural workshops could be very good approaches to help facilitate students' life in the unfamiliar culture setting. What's more, Chinese language course, Chinese culture course, intercultural communication course and similar programs taken consideration in the curriculum of Chinese universities for international students can contributing to meeting the needs of students of different cultural backgrounds.

One of the central aims of this study is to provide managerial and practical insights for Chinese university administrators and academicians, and education policymakers to address the needs of international students at Chinese universities. As confirmed in this study, successful intercultural adaptation of international students is highly connected to the sustainable development of Chinese educational institutions. Considering the impact of globalization on education, the competition among countries to attract more international students becomes of vital importance. Therefore, China, as one of burgeoning regional educational hub needs to employ the most effective strategies to attract international students. It is significant for Chinese higher education institutions to prioritize international students' intercultural adaptation so as to enhance their psychological well-being and academic satisfaction which eventually would be more likely to raise international students' willingness to recommend Chinese educational institutions to others. However, further research is needed to establish the best ways to help improve international students' intercultural communication competence and to provide Chinese universities with knowledge pertinent to provision of appropriate international student support.

\section{Acknowledgements}

This study is supported by the Higher Education Research Funds of Northwestern Polytechnical University under grant No. 2015GJY05 and the Education Science Project of Shaanxi Province 2016 under grant No. SGH16H008.

\section{REFERENCES}

[1] Ward, C., The A, B, Cs of Acculturation. In D. Matsumoto (Ed.), The Handbook of Culture \& Psychology, New York: Oxford University Press, 411-445, 2001.

[2] Chen, H., Che, H. S., \& Yoshida, T., A Review of Factors Impacting Cross-culture Adaption. Advances in Psychological Science, Vol.11, No.6, 704-780, 2003. (In Chinese)

[3] Yang, R.P.-J., Noels, K.A., \& Saumure, K.D., Multiple routes to cross-cultural adaptation for international students: Mapping the paths between self-construals, English language confidence, and adjustment. International Journal of Intercultural Relations. Vol.30, 487-506, 2006

[4] Furnham \& Bochner, Culture Shock. Psychological Reactions to Unfamiliar Environments, Methuen Press, 1986.

[5] Ward, C., \& Chang, W. C., Cultural Fit: A New Perspective on Personality and Sojourner Adjustment. International Journal of Intercultural Relations, Vol.21, No.6, 525-533, 1997.

[6] Ward, C., \& Kennedy, A., Locus of Control, Mood Disturbance and Social Difficulty During Cross-cultural Transition. International Journal of Intercultural Relations, Vol.16, 175-194, 1992

[7] Wang, J., \& Huang, W. H. Cross-cultural adaption of minority bilingual teachers. Journal of Research on Education for Ethnic Minorities, (5), 5-10, 2008.

[8] Ward, C., \& Kennedy, A., The Measurement of Socio-cultural Adaptation, International Journal of Intercultural Relations, Vol. 23, 659-677, 1999. 